ГАДЖИЕВ Ханлар Аляр оглы - преподаватель кафедры политологии и политического управления Института общественных наук Российской академии народного хозяйства и государственной службы при Президенте РФ (119571, Россия, г. Москва, пр-кт Вернадского, 84, корп. 2; gadzhiev_ hanlar@mail.ru)

\title{
К ВОПРОСУ ОБ ЭФФЕКТИВНОСТИ ПРЕЗИДЕНТСКОЙ ВЛАСТИ
}

\begin{abstract}
Аннотация. Статья посвящена проблеме оценки эффективности президентской власти. На основе анализа различных подходов к пониманию эффективности власти и ее критериям предложена методика оценки эффективности института президента. При этом особое внимание уделяется сложностям, возникающим при исследовании эффективности президентской власти. В работе подчеркивается необходимость учета институциональной специфики последней, особенностей систем правления, а также результатов деятельности главы государства как на длительном отрезке времени, так и в текущий период.
\end{abstract}

Ключевые слова: президент, институт президента, эффективность власти, эффективность президентской власти, критерии эффективности власти

$\mathrm{O}$ ценка эффективности власти - одна из наиболее сложных и в то же время важных проблем политической науки, которая имеет теоретическое и практическое значение. Причем, говоря о втором, следует отметить, что оценка эффективности власти необходима, с одной стороны, для государственных органов власти, с другой - для общества: структуры власти на ее основе могут совершенствовать свою деятельность, а общество - контролировать качество деятельности первых [Михайлова 2016: 168].

Эффективность власти, как правило, рассматривается как фактор, влияющий на политическую стабильность [Lipset 1959: 89], социально-экономическое развитие страны, регионов, муниципальных образований и хозяйствующих субъектов [Барциц 2011: 92], легитимность государственной власти [Linz 1978] и т.д. В свою очередь, вопрос эффективности президентской власти имеет особое значение, поскольку институт президента, являясь одним из наиболее значимых институтов политической системы, играет важнейшую роль в политическом процессе многих современных государств. Прежде всего, это касается тех стран, где система государственной власти выстроена таким образом, что главе государства отводится очень широкий круг функций и полномочий.

Исследуя эффективность института президента, необходимо учитывать, что его составляют, во-первых, совокупность формально установленных правил устройства и функционирования президентской власти, а во-вторых, вспомогательные органы и структуры (например, администрация), позволяющие главе государства наиболее эффективно выполнять свою роль в политической системе.

Р. Нойштадт предлагает подход, согласно которому деятельность главы государства следует оценивать, основываясь на нескольких параметрах. Во-первых, каковы были устремления президента, отвечали ли действия главы государства истории, и насколько поставленные им цели соответствовали вехам его времени? Во-вторых, глубоким ли было его «чувство власти», понимание природы власти, и насколько оно укладывалось в реалии той эпохи? В-третьих, как он нес бремя своей должности, что поддерживало его при осуществлении деятельности и насколько взвешенно он принимал решения? Наконец, в-четвертых, каково его президентское наследие, что он оставил после себя, как его деятельность отразилась на институте президента, чем запомнилась его политика, 
какое место ему отведено в истории страны, и как его деятельность повлияла на позиции государства в мире [Нойштадт 2009: 230]?

С одной стороны, такой подход вполне объясним и имеет под собой серьезные основания: без изучения результатов деятельности конкретных президентов невозможно полноценно анализировать президентскую власть. Кроме того, персона президента является центральной составляющей института президента, и то что она вне зависимости от числа вспомогательных органов и их возможностей выходит на передний план - одна из ключевых особенностей президентской власти. Более того, в зависимости от степени институционализации президентской власти влияние конкретных президентов на всю политическую систему может существенно возрастать [Mazzoleni 2000: 326].

С другой стороны, достаточно спорно при оценке эффективности президентской власти игнорировать институциональный аспект. Президентскую власть, ее эффективность, на наш взгляд, необходимо анализировать всеобъемлюще, без отрыва от других составляющих данного института и институциональных механизмов в целом. В пользу этого говорит, в частности, то, что некоторые структуры власти, связанные с институтом президента, сами могут играть серьезную роль в процессе принятия решений главы государства. И наиболее ярким примером в данном случае является администрация президента, которая, будучи призванной обеспечивать реализацию его полномочий, как правило, выполняет функцию подготовки проектов всех его актов (в том числе указов и распоряжений).

Кроме того, эффективность президентской власти необходимо оценивать как по долгосрочным последствиям, так и по краткосрочным, но при условии, что результаты деятельности того или иного главы государства могут быть пересмотрены в дальнейшем именно с учетом долгосрочных последствий [Masciulli, Molchanov, Knight 2009: 9-10].

Еще одним важным моментом, который следует учитывать при исследовании президентской власти, является вопрос о соответствии деятельности главы государства установленным формально-институциональным рамкам. Понятно, что деятельность любого президента не ограничивается лишь формальной плоскостью и, безусловно, это отражается на результатах проводимой им политики, а также влияет на функционирование других институтов власти, с которыми институт президента взаимодействует. Однако то, в какой мере задействованы неформальные практики в политическом процессе, какое они оказывают влияние на функционирование политической системы и насколько объективно востребованы, имеет важнейшее значение для эффективности президентской власти.

Неформальные институты, в частности, могут быть объективно востребованы в период политической трансформации, когда невозможно полностью исключить их функционирование, каким бы успешным ни был политический транзит и как бы удачно ни шел процесс адаптации новых формальных институтов. И здесь сложно не согласиться с В.Я. Гельманом, по мнению которого процесс интеграции и адаптации еще не устоявшихся формальных институтов в новой институциональной среде и, как следствие, не имеющих механизмов самоподдержания, приводит к их определенным дисфункциям. Если при этом не происходит их успешное приспособление, то не исключено, что неформальные практики могут, напротив, упрочить свое положение и укорениться [Гельман 2003: 7].

Вместе с тем, несмотря на объективную необходимость неформальных практик в некоторых случаях и на возможный позитивный эффект для формальных институтов, они не должны превалировать в политическом процессе. 
Весьма значимую сложность для анализа эффективности президентской власти представляют отличия систем правления. В зависимости от их особенностей серьезно отличаются и возможности главы государства. Причем такого рода отличия можно найти не только при сопоставлении президентских, парламентских и смешанных систем правления (т.е. разных типов республик), но также и при сравнении идентичных (с некоторыми оговорками) типов республик. Так, президентская система правления США весьма существенно отличается от президентских систем, установленных в Белоруссии или Бразилии; смешанная система правления Франции достаточно серьезно отличается от той, что установлена России, и т.д. Соответственно, в этих случаях отличаются функции и полномочия главы государства, его возможности в системе государственной власти. Все это значительно затрудняет возможность выведения единых критериев эффективности президентской власти, подходящих к любой модели института президента вне зависимости от установленной системы правления.

Другой и, пожалуй, наиболее серьезной проблемой для исследования эффективности президентской власти является отсутствие единого подхода к пониманию эффективности власти вообще и ее критериям. Так, она может определяться по: 1) качеству предоставляемых государством услуг, степени свободы государственной службы от политического давления, качеству формулирования и осуществления политического курса, уверенности в приверженности государства избранному курсу [Kaufmann, Kraay, Mastruzzi 2010]; 2) политическому процессу (например, стабильности правительства), политическим решениям (например, реформам и инновациям), результатам проводимой политики [Putnam 1993]; 3) степени достижения заявленных целей и стабильности общественной системы [Шабров 2006]; 4) способности властных структур решать экономические, социальные, финансовые, организационные и другие задачи, вести борьбу с коррупцией, согласовывать и координировать экономические и политические интересы различных групп населения [Атаманчук 1998]; 5) степени удовлетворенности народа деятельностью органов власти [Трофимова 2012: 60]; 6) соответствию деятельности власти интересам индивида и общества в целом, демократичности политического режима, успешности реформирования социально-экономической сферы, темпам экономического развития [Суслов 2012: 95]; 7) качеству принимаемых решений, прозрачности и открытости, ориентации на потребителей, уровню координации работы органов государственной власти, использованию информационных технологий и скорости работы, качеству услуг и их доступности для граждан [Коврижных 2008: 28]; 8) целеориентированности института власти, затратам времени на решение управленческих вопросов и осуществление управленческих действий, стилю функционирования государственно-управляющей системы, сложности организации субъекта государственного управления, его подсистем и звеньев, уровню затрат на содержание и обеспечение функционирования системы государственной власти [Хохлов 2007: 14-15]; 9) соответствию установленных норм права ценностям общества и соотношению сил в гражданском обществе, признанию наивысшей ценностью норм, записанных в основных законах, наличию механизмов и органов, способных обеспечивать верховенство закона [Шабо 1993]; 10) удовлетворенности населения [Нагимова 2015: 147] и др.

Как видно из приведенных подходов, критерии эффективности власти могут довольно серьезно отличаться. В немалой степени это связано с рядом объективных проблем, главная из которых - многомерность структуры политических систем. Она не позволяет говорить об эффективности власти вообще, тре- 
бует конкретизации. В частности, невозможно учесть все возможные факторы, влияющие на эффективность.

Некоторые авторы, указывая, что эффективность - это вид отношения, а не свойство или связь, подчеркивают его количественный характер, объясняя это тем, что при сравнении тех или иных результатов всегда говорится о большей или меньшей эффективности [Дуран, Костин 2011].

С таким пониманием эффективности довольно сложно согласиться. Особенно это касается последнего приведенного тезиса об обязательно количественном характере эффективности. Действительно, зачастую об эффективности говорят в компаративных категориях, и при анализе результатов власти может делаться вывод о большей или меньшей эффективности. Однако результат функционирования институтов власти выражается не только в количественных показателях, хотя даже в этих случаях можно говорить о большей или меньшей эффективности. Так, если в качестве анализируемого результата берется политическая стабильность, то ее невозможно измерить посредством количественных методов, но в то же время можно говорить о более либо менее стабильном состоянии политической системы. Степень же стабильности в данном случае может определяться, например, по таким критериям, как наличие/отсутствие правительственных кризисов; наличие/отсутствие институциональных изменений, направленных на трансформацию режима; наличие/отсутствие вызовов режиму со стороны антисистемных сил, склонных к насилию [Sanders 1981: 16-17]; сохранение внутреннего гражданского, межнационального и межконфессионального мира [Семченков 2016: 22] и т.д.

С учетом дискуссионных положений обоих приведенных подходов достаточно гибким на первый взгляд выглядит определение Л.Г. Соколовой, в соответствии с которым эффективность органов власти есть соотношение результатов и общественных целей, результатов и использованных государственных ресурсов [Соколова 2011: 118].

Думается, было бы целесообразным определять эффективность власти через две основные составляющие: 1) степень и сроки достижения целей; 2) соответствие целей интересам общества. Соответственно, говоря непосредственно о президентской власти, ее эффективность необходимо анализировать по степени и срокам достижения поставленных целей, а также по соответствию этих целей общественным потребностям. При этом необходимо учитывать и результаты целеполагания, и результаты целедостижения.

При использовании такого подхода для исследования эффективности института президента в тех странах, где он занимает центральное место в системе государственной власти, необходимо акцентировать внимание, прежде всего, на результатах деятельности главы государства в основных сферах общества - социальной, экономической, политической и т.д. Правда, их необходимо оценивать с учетом того, что президент в большинстве случаев лишь определяет основные направления проводимой политики, тогда как исполнение этих решений ложится на другие структуры власти, причем не только входящие в институт президента. Прежде всего, как правило, это исполнительные органы власти. Однако при определенных условиях сюда также могут относиться высшие органы законодательной власти. Например, в тех случаях, когда глава государства имеет влияние на правящую партию, он фактически может определять основные векторы законодательного процесса. И это не обязательно неформальное влияние: пост президента может совмещаться с лидерством в правящей партии.

Реализуя решения главы государства, указанные органы влияют также на их успешность, на конечный результат. Так, решения президента могут преду- 
сматривать вполне эффективные меры по тем или иным вопросам, но могут быть не выполненными или выполненными ненадлежащим образом данными структурами. В этом случае возникает неопределенность в том, как оценивать эти решения и как их учитывать при оценке эффективности проводимой президентом политики. Более того, сложно определить, что в данном случае более значимо с точки зрения эффективности и что больше повлияло на конечный результат - первоначальные цели, поставленные президентом, или шаги, предпринятые другими структурами власти для их достижения. Иными словами, встает вопрос о том, что более значимо для оценки эффективности власти результаты целеполагания или результаты целедостижения [Fukuyama 2016].

Как представляется, если руководствоваться предложенным подходом, в соответствии с которым эффективность власти предполагает не просто достижение целей, но также их соответствие общественным потребностям, то, конечно, на передний план выходит эффективность целеполагания. Именно в процессе целеполагания определяются цели, а значит на данном этапе и решается вопрос об их соответствии общественным потребностям.

При анализе соответствия поставленных главой государства целей социальным потребностям важнейшим индикатором становится уровень его общественной поддержки. Последний можно проследить, прежде всего, по итогам президентских выборов (иногда также по результатам парламентских выборов, если в них участвует партия, возглавляемая президентом или ассоциирующаяся с ним), результатам инициируемых главой государства референдумов, его рейтингу и т.д. В качестве дополнительного показателя можно учитывать уровень поддержки оппозиции.

Если согласно общественному мнению действующая власть эффективна, то высока вероятность повышения значимости установленной модели власти и политических институтов. Если же она неэффективна, то, напротив, отношение общества к последним может стремительно измениться в худшую сторону [Dahl 1971: 149]. Аналогичным образом можно говорить и о президентской власти: отношение общества к институту президента может меняться в зависимости от результатов деятельности того или иного главы государства, его эффективности [Poguntke, Webb 2005].

Таким образом, оценка эффективности президентской власти представляет собой особую сложность и требует учета множества факторов, среди которых первостепенное значение имеют ее институциональные особенности и специфика политической системы. При этом необходимо анализировать не только степень и сроки достижения главой государства целей, но также соответствие этих целей интересам общества.

\section{Список литературы}

Атаманчук Г.В. 1998. Критерии социальной эффективности управления. Проблемы повышения эффективности государственного и муниципального управления в современной России. Ростов н/Д.

Барциц И.Н. 2011. Социальная эффективность государственного управления: модели, критерии, российский опыт внедрения. - Проблемы управления (Минск). № 1(38). С. 92-100.

Гельман В.Я. 2003. Институциональное строительство и неформальные институты в современной российской политике. - Полис. Политические исследования. Т. 4. № 4. С. 6-25.

Дуран Т.В., Костин В.А. 2011. К вопросу о понятии «эффективности» в процессе управления. - Научный вестник Уральской академии государственной службы: политология, экономика, социология, право. № 15. С. 138-143. 
Коврижных И.В. 2008. Эффективность и качество государственного управления: теоретический аспект. - Алтайский вестник государственной и муниципальной службы. № 1. С. 26-28.

Михайлова О.В. 2016. Основные направления развития государственного управления в РФ и его эффективность. - Инновационная экономика: перспективы развития и совершенствования. № 1(11). С. 166-172.

Нагимова А.М. 2015. Эффективность деятельности органов государственного управления: методика оценки. - Научные труды Центра перспективных экономических исследований. № 9. С. 146-151.

Нойштадт Р. 2009. Президентская власть и нынешние президенты. М.: Московская школа политических исследований. 463 с.

Семченков А.С. 2016. Политическая стабильность как приоритет обеспечения национальной безопасности России. М.: МАКС Пресс. 248 с.

Соколова Л.Г. 2011. Эффективность государственного и муниципального управления. - Известия Иркутской государственной экономической академии. № 6. С. 117-120.

Суслов М.Г. 2012. Взгляды на эффективность работы органов власти в зарубежных странах. - Ars Administrandi. № 4. C. 94-100.

Трофимова И.Н. 2012. Эффективность местного самоуправления в Российской Федерации и проблема гражданского участия. - Ars Administrandi. № 1. С. 55-63.

Хохлов А.А. 2007. Рациональность и эффективность государственного управления. - Среднерусский вестник общественных наук. № 1. С. 13-15.

Шабо Ж.Л. 1993. Государственная власть: конституционные пределы и порядок осуществления. - Полис. Политические исследования. № 3. С. 155-165.

Шабров О.Ф. 2006. Легитимность политической власти как фактор ее эффективности. - Демократия, безопасность, эффективное управление: новые вызовы политической науке: тезисы докладов IV Всероссийского конгресса политологов. Москва. 20-22 октября 2006. М.: Российская ассоциация политической науки. 480 с.

Dahl R.A. 1971. Polyarchy: Participation and Opposition. New Haven: Yale University Press. 257 p.

Fukuyama F. 2016. Governance: What Do We Know, and How Do We Know It? Annual Review of Political Science. Vol. 19. P. 6.1-6.17.

Kaufmann D., Kraay A., Mastruzzi M. 2010. The Worldwide Governance Indicators: Methodology and Analytical Issues. - The World Bank Development Research Group Macroeconomics and Growth Team. Policy Research Working Paper 5430. URL: http:// info.worldbank.org/governance/wgi/pdf/WGI.pdf (accessed 15.07.2018).

Linz J.J. 1978. Crisis, Breakdown and Reequilibration. - The Breakdown of Democratic Regimes (ed. by J.J. Linz, A. Stepan). Baltimore, MA: Johns Hopkins University Press. 144 p.

Lipset S.M. 1959. Some Social Requisites of Democracy: Economic Development and Political Legitimacy. - The American Political Science Review. Vol. 53. No. 1. P. 69-105.

Masciulli J., Molchanov M.A., Knight W.A. 2009. Political Leadership in Context. The Ashgate Research Companion to Political Leadership. P. 3-27.

Mazzoleni G. 2000. A Return to Civic and Political Engagement Prompted by Personalized Political Leadership? - Political Communication. Vol. 17. No. 4. P. 325328.

Poguntke T., Webb P. 2005. The Presidentialization of Politics in Democratic Societies: A Framework for Analysis - The Presidentialization of Politics. A Comparative Study of Modern Democracies. Oxford: Oxford University Press. 384 p. 
Putnam R. 1993. Making Democracy Work: Civic Traditions in Modern Italy. Princeton, NJ: Princeton University Press. 258 p.

Sanders D. 1981. Patterns of Political Instability. N.Y.: St Martin's Press. 244 p.

GADZHIEV Khanlar Alyar ogly, Lecturer at the Chair of Political Science and Political Management, School of Social Science, Russian Presidential Academy of National Economy and Public Administration (bld. 2, 84 Vernadskogo Ave, Moscow, Russia, 119571; gadzhiev_hanlar@mail.ru)

\section{TO THE ISSUE OF THE EFFECTIVENESS OF THE PRESIDENTIAL POWER}

Abstract. The article is devoted to the problem of assessing the effectiveness of presidential power. Basing on the analysis of different approaches to the view of factors of the effectiveness of power and its criteria, the author proposes a method for assessing the effectiveness of the presidency. At the same time, special attention is paid to the difficulties arising in the study of the effectiveness of the presidential power. The work emphasizes the need to take into account the institutional specifics of the presidential authority, features of the system of government, as well as the results of the activities of the head of state, both for a long-term and current period.

Keywords: president, presidency, government effectiveness, effectiveness of presidential power, criteria of government effectiveness 